\title{
Subjects with colour vision deficiency in the community: what do primary care physicians need to know?
}

\author{
Xin Bei V Chan ${ }^{1}$, Shi Min S Goh ${ }^{1}$ and Ngiap Chuan $\operatorname{Tan}^{2,3^{*}}$
}

\begin{abstract}
Background: Congenital colour vision deficiency (CVD) has a prevalence of $8 \%$ for men and $0.4 \%$ for women. Amongst people born with normal colour vision, the acquired form of CVD can also affect them at later stages of their lives due to disease or exposure to toxin. Most CVD persons have difficulties dealing with colours in everyday life and at work, but these problems are under-reported due to a lack of its awareness in the general population. This literature review seeks to present findings of studies and reports on the impact of CVD on the affected persons chronologically through different stages of their lives and their coping measures.

Methods: Scientific publications and corresponding references relating to how CVD affects individuals were searched, identified and retrieved from PubMed, National University of Singapore and Cochrane electronic databases. Books that were not available electronically were manually searched. Paramedical literature was also included through online searches using Google and Google Scholar. Inclusion criteria were English-based studies pertaining to effects of CVD on everyday life and respective coping measures, including experimental, observational studies, symposium proceedings and systematic review. There was no timeframe restriction for these publications. Articles using anecdotal evidence were excluded with the exception of those used to describe the effects of CVD on play age and school age. Our literature search found 136 articles, 60 of which were used in this review based on the respective selection criteria.
\end{abstract}

Results: CVD affects many aspects of life from childhood to adulthood. The implications extend across play, sports, driving, education, occupation, discrimination, and health and safety issues. Awareness of CVD helps to identify and develop corresponding coping strategies.

Conclusions: More work needs to be done in raising awareness of CVD and its implications, as well as implementing measures to overcome these difficulties.

Keywords: Colour vision deficiency, Activities of daily living, Coping measures

\section{Background}

Individuals with normal colour vision $(\mathrm{NCV})$ have three types of specialised cells, known as cones, in their retina to help them to perceive red, green and blue colours. People with abnormal cones will perceive colours differently. There are several types of such colour vision deficiency (CVD). Anomalous trichromacy occurs when one of the three

\footnotetext{
* Correspondence: tan.ngiap.chuan@singhealth.com.sg

${ }^{2}$ Research Department, SingHealth Polyclinics Head Office, 167 Jalan Bukit

Merah, Connection One Tower 5, \#15-10, Singapore 150167, Singapore

${ }^{3}$ DUKE-NUS Graduate Medical School, 8 College Rd, Singapore 169857,

Singapore

Full list of author information is available at the end of the article
}

cones is abnormal - protanomaly involves reduced sensitivity to red, deuteranomaly involves reduced sensitivity to green and tritanomaly involves reduced sensitivity to blue. Dichromacy occurs when a person only has two retinal cones that are able to perceive colour, resulting in the total absence of one colour. There are three types of dichromacy - protanopia, deuteranopia, and tritanopia.

Congenital CVD has a prevalence of $8 \%$ for men and 0.4\% for women [1]. In Singapore, a study done on 1249 children aged 13-15 years using the Ishihara 24-plate edition book found $5.3 \%$ of boys and $0.2 \%$ of girls to be colour blind [2]. All people with CVD, except for a few 
mildly affected deuteranomals, report that they encounter problems with colour perception in everyday life and at work [3]. Yet, there have been few studies systematically documenting the personal difficulties that CVD persons experience in their daily lives [4]. There seems to be a lack of awareness for the implications of CVD in the general population $[1,5]$. Furthermore, CVD can develop later in life due to development of disease or exposure to toxins such as chemicals or drugs which affect the retinal cellular structure and function [6-9]. Known as acquired colour vision impairment (ACVI), the prevalence of CVD, inclusive of both the congenital and acquired forms, is expected to increase globally with the increasing population. Therefore, this article presents a review of current literature, comprising scientific studies and paramedical reports of the effects of CVD on individuals through their different stages of life. This would better help those afflicted with CVD to identify the domains of difficulties in daily living and to determine possible strategies to cope with their predicaments.

\section{Methods \\ Data sources}

Studies on how CVD affects well-being were identified from multiple sources. The following electronic databases were searched: PubMed database, National University of Singapore (NUS) database and Cochrane database of systematic reviews. Search terms included 'colour vision deficiency,' 'colour vision impairment', 'colour blindness', 'well-being,' 'quality of life, 'everyday life, 'everyday tasks,' 'discrimination,' 'handicap,' 'education, 'driving,' 'accidents,' 'occupation,' 'aviation', 'maps'. The last search was performed on 22 May 2013. The references within the retrieved articles found were also searched. Additionally, electronic journals in the field of CVD that were available online were searched. Books that were not available electronically were hand searched for relevant studies. We also used the proceedings of the eleventh and thirteenth Symposiums of the International Research Group on Colour Vision Deficiencies, held in Sydney (1991) and France (1995) respectively. Paramedical literature was included through online searches on the World Wide Web, using search engines such as Google and Google Scholar. All literature found was added to EndNote X6 digital library.

\section{Study selection}

Inclusion criteria were articles available in English language, studies pertaining to effects of CVD on everyday life and specific populations (for example, pilots). These publications consist of experimental, observational studies, symposium proceedings and systemic review. No restrictions on the years of study/follow-up, publication status or publication date were imposed. There was no timeframe indicated as some studies done on CVD decades ago have implications that remain pertinent today. The exclusion criteria used were non-English articles and non-human studies. Articles using anecdotal evidence were also excluded with the exception of those used to describe the effects of CVD on play age and school age due to the paucity of primary sources of evidence for these stages of life. Eligibility assessment was performed by two unblinded reviewers. Disagreements between reviewers were resolved by consensus.

The literature search on electronic databases provided a total of 118 citations. Additional 18 records were identified through hand searches, reference lists and search engines on the World Wide Web. After adjusting for duplicates, 124 remained. Of these, 52 were excluded as they were not within the scope of the review, their full text was not available or not translated into English. The full texts of the remaining 72 citations were examined in detail. It appeared that 12 did not meet the inclusion criteria as they were not relevant to the topics of discussion. Eventually, 60 records met the inclusion and exclusion criteria and were used in this review. Of these 60, 46 were identified via electronic databases while 14 were identified from alternative sources as mentioned earlier. The selection of studies is summarised in Figure 1 below.

Each article was evaluated using the PICOS framework (population, interventions, comparator, outcome and study design).

\section{Limitations}

No review protocol was used hence there may be bias incurred in review methods in the post hoc decisions. Publication bias and outcome reporting bias have been well documented and may overestimate the effects of CVD in the included studies $[10,11]$.

\section{Results}

The impact of CVD on affected persons will be presented chronologically from childhood at play and in schools, young adulthood, working life to late adulthood. Figure 2 summarises the impact of CVD on affected individuals at different stages of their life.

\section{Play age}

A child engages play and learning during childhood. They are often exposed to colourful objects such as toys and accessories during these activities. A child with deuteranomaly, the commonest form of colour-blindness, will be able to accurately name only four colours within a box of 24 coloured pencils. Nevertheless, they will probably be able to guess more [12]. Consequently, parents of CVD children often reported that their children were mistaken as slow learners or ridiculed in preschool for mixing colours up and colouring objects wrongly [13,14]. Such 


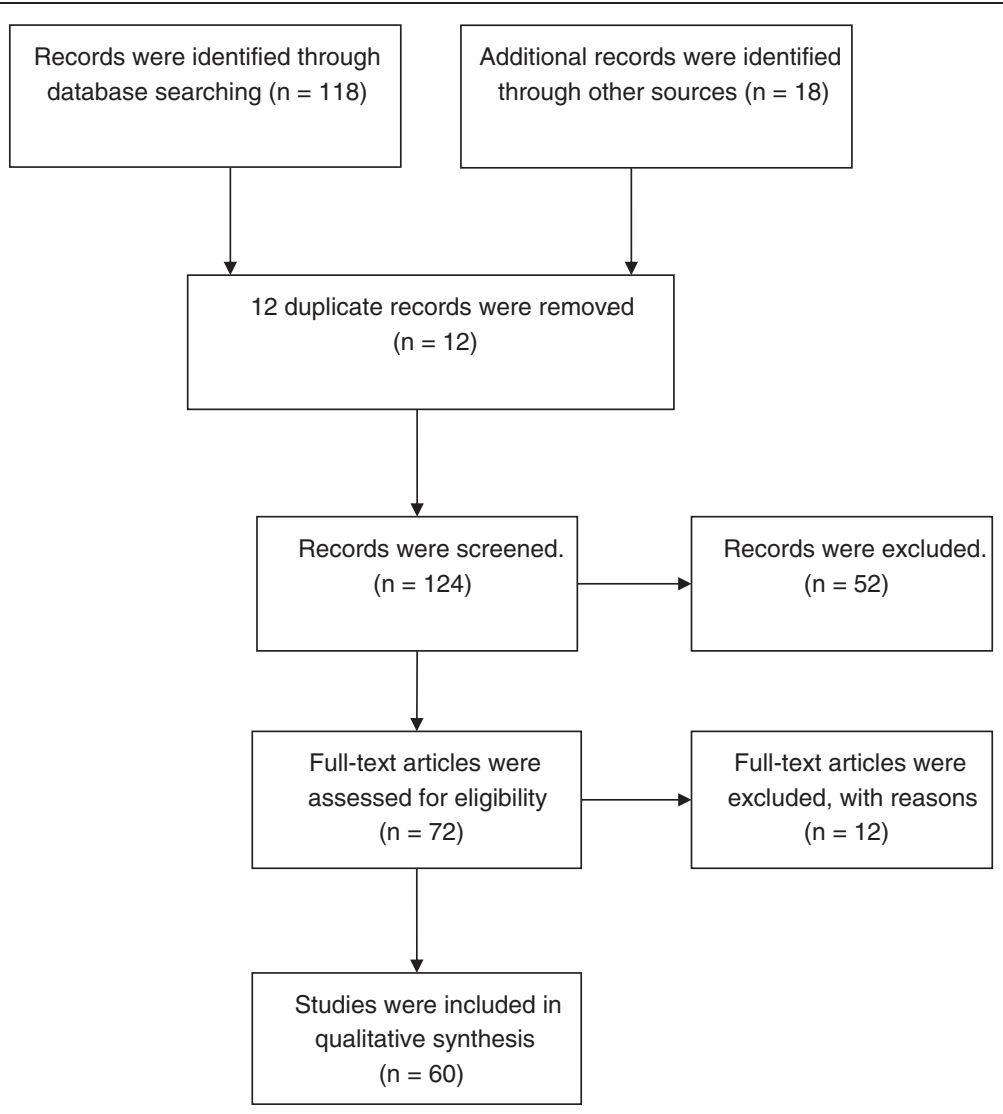

Figure 1 Flow diagram of study selection.

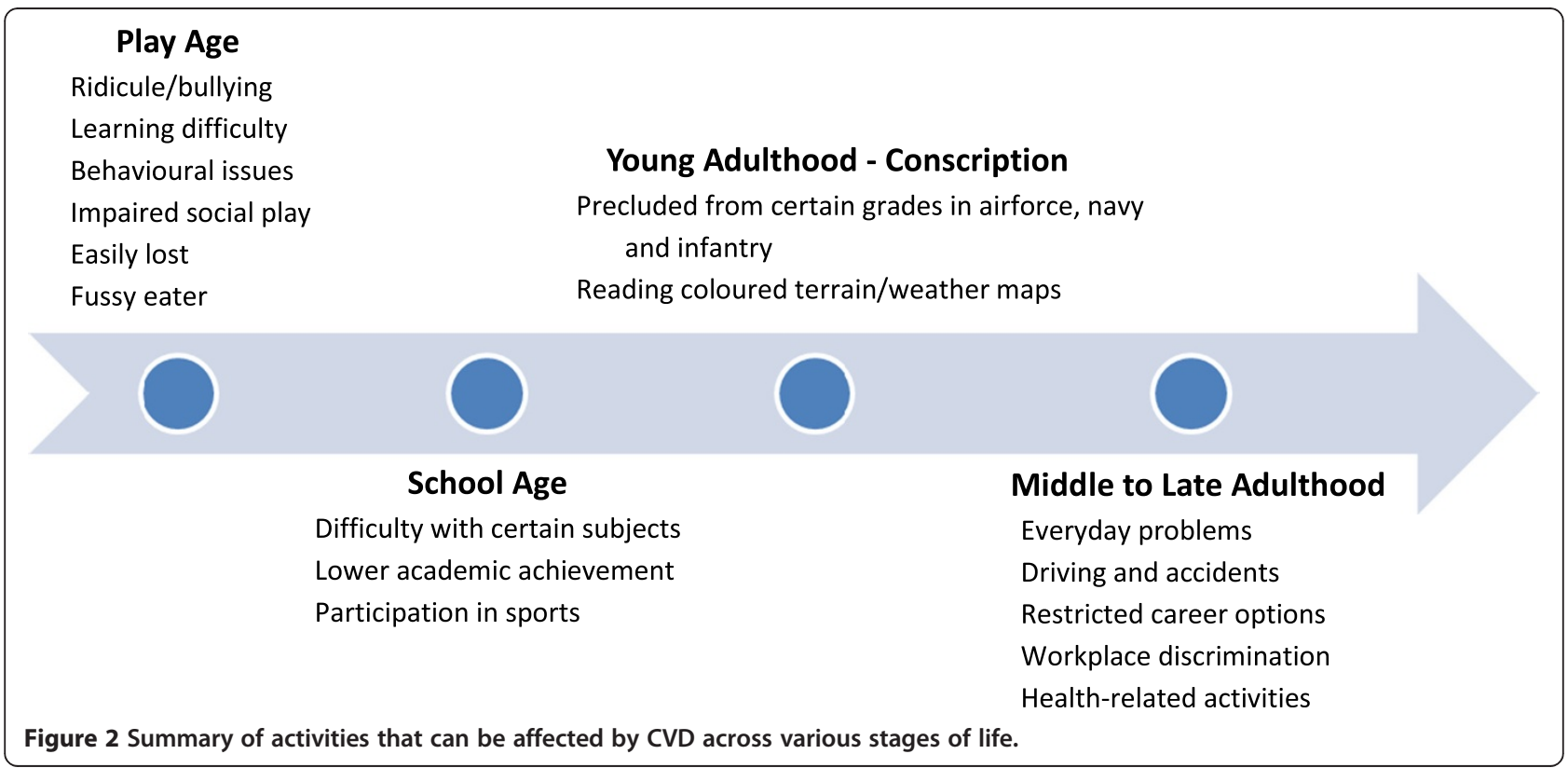


mistakes may cause embarrassment to the child and lead to significant consequences such as school refusal or social withdrawal.

Other learning difficulties include inability to accurately describe things around them, failure to follow instructions relating to colour and to read coloured printing against a coloured background [12]. This will translate into practical problems such as difficulty completing workbook tasks relating to colour, and even cheating in tests because the child is unable to tell the questions written in coloured ink or chalk on the board [14].

In Parten's classification of stages of play, activities such as associative and cooperative play, which involves interpersonal interactions, are critical stages of social development. However, CVD children may face difficulties when playing with others because they cannot differentiate between different teams distinguished by coloured tags, nor recognise coloured pieces in board games [14].

In the area of personal safety, CVD children may get lost more easily if given directions using coloured objects as signs [14]. CVD children may also be fussy about eating certain food, for example, vegetables, because they perceive these foods in unpalatable colours [12]. The effect on the choice of food should not be overlooked in a phase whereby proper nutrition is important for the child's growth.

\section{School age}

Most children with CVD are unaware of their condition, with many only realising so when they are in secondary school [12]. Steward and Cole in their study showed that $49 \%$ of dichromats and $8 \%$ of anomalous trichromats became aware of their CVD in primary school, with a further $22 \%$ of dichromats and $28 \%$ of anomalous trichromats in secondary school [4]. They also showed that $71 \%$ of dichromats and $27 \%$ of anomalous trichromats began to suspect having CVD after they encountered difficulties with colour [4]. However, $77 \%$ and $94 \%$ respectively had a clear diagnosis of CVD only after formal colour vision testing [4]. Upon diagnosis, they often retrospectively recall the difficulties they faced with discriminating colours in earlier life [4].

CVD students struggle in a variety of subjects, especially the sciences. Sullivan (2011) noted that CVD children tend to lag behind in many subjects where colour is used as a teaching tool, including mathematics, science, geography, reading, sport and food technology [12]. The common difficulties faced by CVD students in academic subjects are summarised in Table 1 [13-17].

Nonetheless, studies which aimed to determine the impact of CVD on academic achievement showed conflicting outcomes, possibly due to differences in study designs. A 1969 case control study showed no significance difference between $\mathrm{NCV}$ and CVD children in
Table 1 Common difficulties faced by CVD students in academic subjects

\begin{tabular}{ll}
\hline Subject & Areas of difficulties \\
\hline Art & Unable to appreciate how colours are used \\
& Use of wrong colours when painting \\
Chemistry & Unable to read litmus paper accurately \\
& Unable to tell the colours of different chemical solutions in \\
& quantitative analysis \\
& May be unable to identify metals by colour of flame \\
& produced when a metal is burnt \\
Biology & Unable to accurately read stained slides under microscope \\
& May not be able to identify species of plants \\
& May not be able to accurately carry out dissections \\
& May have difficulty understanding coloured diagrams in \\
& textbooks \\
Phill have difficulty with coloured wiring and use of prisms & Unable to read pie charts and graphs
\end{tabular}

Data from Dutton F [13], Waggoner TL [14], Sullivan K [15], Albany-Ward K [16], Spalding JAB [17].

intelligence scores and elementary school achievement [18]. A literature review conducted in 1992 reported that studies attempting to relate CVD to learning difficulty were equivocal in their outcome [19]. A subsequent study in 1998 showed significantly lower general academic scores among 82 children with CVD as compared to 82 children with $\mathrm{NCV}$, matched by age and class [20]. In contrast, a 2004 cohort study on 499 CVD children found that CVD did not cause significantly lower scores in mathematics and reading at 7 years and 16 years of age respectively, even after adjusting for birth-weight, social class at birth, family size, and parental education [21]. Furthermore, the highest educational qualification was not significantly associated with colour vision status [21]. Another 2004 questionnaire survey showed no significant difference in the disciplines studied between NCV and CVD persons, but CVD interviewees tended towards technical studies (30\%, as opposed to $18 \%$ of NCV subjects), and less of them undertook tertiary education in university $(68.9 \%$, as opposed to $79.9 \%$ of NCV subjects) [22].

CVD-related difficulties during the schooling years are common and are observed in a variety of sports. In an Australian study on 102 CVD subjects, one in four reported difficulties with sporting activities [4]. Confusion arises due to inability of CVD players to differentiate their team members from the opponents wearing coloured uniforms. The former also tend to lose orange golf balls in the grass, and mistake red for brown snooker balls $[4,12,23]$.

\section{Young adulthood during military service}

Colour vision is involved in a variety of military activities and training. Certain vocations in the air-force, navy and infantry require normal colour vision $[23,24]$. Those 
commonly affected are military personnel in the aviation and maritime divisions of the defence force.

In aviation, a Farnsworth lantern test is routinely used to screen colour vision and involves identification of a pair of lights consisting of combinations of red, green or white. The Precision Approach Path Indicator (PAPI) signal system tells pilots whether their aircraft is above, below, or on the correct approach path for landing. It displays four signal lights that can be red or white. A case-control study was performed on 52 CVD subjects and 52 subjects with NCV in 2008: amongst CVD subjects who passed the Farnsworth lantern, they made significantly more errors naming PAPI signals than NCV subjects and $80 \%$ of them made more errors than the worst performing NCV subject [25]. Another study showed that CVD observers made significantly more errors and were slower in completing tasks requiring processing of colour coded electronic flight information [26].

The Holmes-Wright lantern type A ( $\mathrm{H}-\mathrm{W} \mathrm{A})$ is an occupational colour vision test used by the UK Civil Aviation Authority (CAA) and approved by Joint Aviation Requirements (JAR) to select aircrew. The Commission Internationale d'Eclairage (CIE) recommends that the Falant pass criteria be used with all approved lanterns. However, a 2008 study showed that this investigation and selection criteria used by the UK CAA and CIE do not identify individuals with superior colour discrimination ability and lack internal consistency [27]. There is thus no evidence to suggest that successful CVD applicants have significantly better colour discrimination ability than CVD people who fail. The selection process is therefore potentially unfair to CVD persons applying for aviation positions.

In navy, CVD persons have difficulty recognising redgreen-white maritime signals. The Holmes-Wright Type $B$ lantern is the standard colour vision test used by the Board of Trade in maritime industry [28]. A 1983 study that validated the Holmes-Wright Type B lantern test as a discriminating test showed that all CVD persons failed, except for a few mild deuteranomals [28]. This correlates with other studies which also showed that all CVD persons, except for a few mild deuteranomals, make errors recognising maritime signals $[29,30]$. Furthermore, the rate of errors increases with decreasing signal illuminance $[29,30]$. Both protanopes and protanomals have significantly reduced visual range for red signals [29,31]. Kinney, Paulson and Beare showed that only $40 \%$ of deutans and $14 \%$ of protans performed as well as their worse performing NCV subjects [29]. It is largely accepted that normal colour vision is essential for safe maritime navigation.

Inherited CVD is marked by a difficulty in discerning red from green, while acquired CVD leads to decreased ability to distinguish blue from green. CVD persons struggle with reading coloured maps, although a monochromatic map appears the same to a CVD user as it does to one with NCV [32]. Although map reading among CVD users has not been studied extensively, it was found that readers with CVD made more errors naming the boundary lines on multi-coloured terrain maps [33]. Another study showed that only a small percentage of CVD readers could name the colours of a weather radar display without error [34]. CVD persons are slower and less successful in search tasks, when colour is the primary attribute of the target object, or if colour is used to organize visual displays $[3,35]$.

\section{Middle to late adulthood \\ Activities of daily living}

Nearly $90 \%$ of dichromats and up to two-thirds of anomalous trichromats reported difficulties with everyday tasks that involve colour [4]. Tables 2 and 3 show the difficulties reported by persons with CVD, and the difficulties subanalysed within each subtype of CVD [4,22].

Even amongst $\mathrm{NCV}$ individuals during the early part of life, they can develop CVD as they age. Acquired CVD or ACVI can occur due to age-related crystalline changes in lens, age-related maculopathy and conditions such as diabetes, glaucoma and optic neuritis. They can also be caused by medications such as digoxin, sildenafil, chloroquine and ethambutol. ACVI are often tritan (blue-yellow) in nature. Tritan defects cannot be detected using the Ishihara chart. Instead, the Hardy, Rand and Rittler plates may be more useful as tritan plates are also included and the severity of the defects can be graded [6]. Alternatively, the Farnsworth D15 test may be used [6].

\section{Driving and accidents}

Safe driving requires the driver to recognise colour-coded traffic lights and road signage. A case control study showed that both CVD and NCV subjects who were qualified to drive were in similar proportions ( $83.4 \%$ and $83.8 \%$

\section{Table 2 Difficulties in everyday life reported by 151 CVD subjects and 302 NCV subjects}

\begin{tabular}{|c|c|c|c|}
\hline Difficulties associated with & $\begin{array}{l}\text { \% of CVD } \\
\text { observers }\end{array}$ & $\begin{array}{l}\text { \% of NCV } \\
\text { observers }\end{array}$ & $\begin{array}{l}\text { Significance } \\
\text { ( } p \text { value) }\end{array}$ \\
\hline Clothing colours & 23.8 & 1.0 & $<0.0001$ \\
\hline $\begin{array}{l}\text { Workplace/hobbies colours eg. } \\
\text { pie charts }\end{array}$ & 13.2 & 1.0 & $<0.0001$ \\
\hline Natural colours & 40.4 & 1.0 & $<0.0001$ \\
\hline $\begin{array}{l}\text { Colours relating to cooking s eg. } \\
\text { Identification of cooked versus } \\
\text { raw meat }\end{array}$ & 31.7 & 8.6 & $<0.0001$ \\
\hline $\begin{array}{l}\text { Sports colours eg. shirts of } \\
\text { players }\end{array}$ & 21.2 & 1.3 & $<0.0001$ \\
\hline Skin colours & 3.3 & 1.7 & 0.0007 \\
\hline Television colours setting & 6.0 & 0.7 & 0.0002 \\
\hline
\end{tabular}

Data from Tagarelli et al. [22] (Statistical significance of differences were calculated using the chi-square test or Fisher exact test, two-tailed significance level 0.05) 
Table 3 Percentage of subjects with different types of CVD reporting difficulty in everyday tasks

\begin{tabular}{|c|c|c|c|c|c|}
\hline Difficulties associated with & $\begin{array}{l}\text { Dichromats }(\%) \\
(\mathrm{n}=37)\end{array}$ & $\begin{array}{l}\text { Anomalous trichromats }(\%) \\
(n=65)\end{array}$ & $\begin{array}{l}\text { Protans }(\%) \\
(\mathrm{n}=36)\end{array}$ & $\begin{array}{l}\text { Deutans }(\%) \\
(n=66)\end{array}$ & $\begin{array}{l}\text { NCV (\%) } \\
(n=102)\end{array}$ \\
\hline Clothing/goods colours & 86 & 66 & 78 & 71 & 0 \\
\hline Workplace/hobbies colours & 68 & 23 & 50 & 33 & 0 \\
\hline Plant/flower identification & 57 & 18 & 44 & 26 & 0 \\
\hline Ripeness of fruits and vegetables & 41 & 22 & 31 & 27 & 0 \\
\hline Cooked versus raw meat & 35 & 17 & 33 & 20 & 0 \\
\hline Sports colours & 32 & 18 & 19 & 23 & 0 \\
\hline Adjust television colour settings & 27 & 18 & 28 & 18 & 2 \\
\hline Skin colours eg. sunburn, rashes & 27 & 11 & 17 & 17 & 0 \\
\hline $\begin{array}{l}\text { Previously taken wrong medication due to colour } \\
\text { difficulties }\end{array}$ & 0 & 3 & 3 & 1 & 0 \\
\hline
\end{tabular}

Data from Steward and Cole [4].

respectively) [22]. However, regular use of a car was significantly less common among CVD subjects than NCV subjects [22].

Reading road traffic signals tend to be less difficult for CVD observers compared to maritime, aviation and rail signals because the former is viewed from much shorter distances. Furthermore, they are assisted by cues such as position of traffic lights, relative brightness and movement of other traffic $[3,4,36]$. Nevertheless, experimental studies have shown that people with CVD make more errors recognizing the colours of road traffic signals than those with normal vision $[37,38]$. Deuteranopes have significantly reduced ability to notice red, orange and green colour-coded traffic control devices compared to NCV subjects [39]. Protans are known to have reduced visual range for red signals compared to NCV observers [36,40]. About 18-20\% of anomalous trichromats and 50-60\% of dichromats admitted to difficulty recognizing road traffic signals while $10-15 \%$ of protans admitted to difficulty seeing red signal lights $[4,23,41]$.

Atchison DA et al. showed that response times and error rates for recognising red and yellow lights were increased in CVD subjects compared to NCV subjects [38]. On the contrary, Tagarelli et al. showed there were no differences between the two groups in identifying the colours of traffic light signals. However, when the relative positions of the traffic lights were changed, more CVD subjects had difficulty identifying the colours than NCV subjects but the difference was not statistically significant [22].

Significantly higher proportion of CVD subjects preferred daytime driving over night-time driving compared to NCV subjects [22]. This could be due to difficulty identifying the reflectors on the road and identifying the lights of the car ahead at night [22]. Confusion of traffic lights and street lights was also noted in one-third of CVD drivers [4]. The detection of dashboard warning lights (which are often red) was significantly more difficult for protans than deutans (17\% versus 3\% respectively) [4].
In terms of accident rates, studies reported that CVD drivers did not have more road traffic accidents than NCV drivers [21,22,36,42]. However, protans showed significantly more rear end collisions and accidents by overlooking red rear, stop and warning lights than colour normal [36]. Rear end collisions seemed more prevalent amongst protans because the red lights of the rear end appeared dimmer to them, resulting in delayed perception in poorly illuminated areas. Deutans caused more accidents than NCV drivers at traffic light controlled intersections, although this was not statistically significant [36]. A case control study also showed that there was no increased risk of unintentional workplace injuries amongst CVD subjects [21].

\section{Restriction of career options and workplace discrimination}

Individuals with CVD appeared to have restricted career options. A 1971 study found that only 214 out of 569 CVD subjects made suitable choices of career [43]. Table 4 shows careers and occupations known to be affected by CVD $[23,24]$. The Commission Internationale de L'Éclairage recommends that normal colour vision be a prerequisite for pilots of scheduled passenger aircraft, especially large aircraft, and is mandatory for other commercial pilots to pass a lantern test and should not have a protan (red-deficient) colour vision deficiency [44].

According to Birch, coloured signals may be preferred to short wavelength radio for communication in the armed forces because radio signals can be intercepted [23]. Hence, vocations such as signals personnel and again aircraft pilots will be unsuitable for individuals with CVD.

In the railway industry, train drivers and other rail workers must be able to recognize red, yellow and green signals at distances up to $1 \mathrm{~km}$, sometimes under conditions of poor visibility due to fog or rain. Hovis $\mathrm{JK}$ and Oliphant D reported that $97 \%$ of individuals with CVD failed a lantern test (CNLAN) that was found to provide a reasonable functional assessment of colour discrimination 
Table 4 Career and occupations known to apply a colour vision standard

NORMAL COLOUR VISION

COLOUR VISION STANDARD

APPLIED BUT ACCEPTS SOME WITH

SLIGHT CVD

OCCUPATIONS WHERE CVD IS A DISADVANTAGE AND COLOUR VISION STANDARD MAY APPLY controllers, technical and

maintenance staff at airports, aircraft pilots and engineers in the armed services, naval officers, submarine personnel, masters and vessels, customs and excise officers, train drivers, railway engineers and maintenance staff; workers in industrial colour quality assurance and colour matching, workers in fine art reproduction and photography, some electrical and electronic engineers

Fire fighters, police officers, some electrical and electronic engineers, some ranks in the armed services, hospital laboratory technicians, merchant seamen

Art teaching, bacteriology, botany, chemistry, interior design, histopathology, horticulture,
Commercial airline pilots, air traffic watchkeepers on merchant marine geology, diamond grading, metallurgy

Data from Birch J [23] and Health Promotion Board of Singapore [24].

for the rail industry [45]. Vingrys AJ and Cole BL, in their literature review to determine whether colour vision standards were justified for the transport industry, found that CVD observers made more errors and had significantly slower reaction times in recognising coloured signal lights [46]. It concluded that there was sufficient evidence to warrant retention of colour vision standards in transport industries where the highest standards of safety are expected.

Severe CVD is generally unacceptable in the police force. Conflict of evidence regarding identification of clothing or vehicles or items using colours at the scene of crime may interfere with jurisdiction in criminal or forensic cases [23].

CVD applicants can be recruited as fire fighters if they pass the Ishihara's test. Should they fail this colour vision test, they would have to undertake the Farnsworth-Munsell Standard D15 test (FMD-15) [47-49]. Protans are not accepted in the fire brigade because of their reduced visibility of red signs and traffic signals. In addition, oxygen (black) and acetylene (maroon) gas cylinders are similar in shape and might be confused due to this CVD [49]. Other critical tasks which require colour discrimination among the firefighters include interpretation of computer displays in communications units, assessment of gas level in gas detectors, use of indicator papers, identification of zone of fire on building evacuation and fault indicator panels, deduction of the burning substance based on the colour of the smoke and flames and distinction of hydraulic and pressure hoses, fire extinguishers, gas cylinders, pipes, ducts, and triage labels [47].
Even among healthcare professionals, CVD can be disadvantageous to doctors and dentists. Difficulties faced by CVD doctors and medical students are summarised in Table $5[5,17]$.

CVD doctors tend to avoid the following specialties where normal colour vision is important: histopathology, microbiology, haematology, dermatology, ophthalmology, surgery, anaesthesia (uses differently coloured gas tanks) [17]. A 1990 case control study showed that CVD dentists made significantly more errors in the hue and chroma aspects of shade selection, hence affecting their ability to select prosthetic teeth to match natural teeth [50]. Hue is the quality that distinguishes one family of colours from another based on their different wavelengths in the visible spectrum. Chroma is the saturation, intensity, or strength of the hue.

Nearly one-quarter of CVD subjects reported having colour difficulties in previous jobs, as well as being precluded from an occupation because of their CVD [4]. Steward and Cole showed that $43 \%$ of dichromats and $29 \%$ of anomalous trichromats reported their CVD had affected their choice of career [4]. 46\% of dichromats and $15 \%$ of anomalous trichomats also reported colour difficulties with everyday work, and this was statistically significant when compared with NCV subjects [4].

However, a 2004 questionnaire survey revealed that CVD people had little difficulty in maintaining permanent employment [22]. Nonetheless, they were more likely to hold subordinate jobs, for example, as agents, clerks or servants, whereas NCV subjects preferred autonomous activities, such as commercial and trade work [22]. A subsequent study in 2005 also revealed that there was no significant difference between proportion of CVD

\section{Table 5 Difficulties faced by CVD doctors and medical} students

\begin{tabular}{ll}
\hline No. & Difficulties faced by CVD doctors and medical students \\
\hline 1 & Body colour changes: pallor, cyanosis, jaundice \\
3 & Skin rashes, erythema and lymphangitis \\
4 & Ophthalmology: disc pallor, diabetic changes, haemorrhage versus \\
& $\begin{array}{l}\text { pigmentation, glaucoma, haemorrhage in anterior chamber, Kayser } \\
5\end{array}$ \\
6 & Body products: blood versus bile in urine, faeces, sputum, vomit \\
7 & Microscopy \\
8 & Mouth and throat conditions \\
9 & Ishihara test giving \\
10 & Chemistry end-points \\
11 & Tissue identification in surgery \\
12 & Gangrene and sores \\
\hline
\end{tabular}

Data from Spalding $[5,17]$. 
and NCV people in the major occupational groups except for transport operations, aircraft and ship officers, electrical and electronic engineering, as well as fibre and textile processing [51].

\section{Health-related activities}

The effect of colour on appetite is important because poor growth and malnutrition due to poor oral intake, can affect the young and old respectively. Colour perception of food can adversely affect the appetite and taste perception of CVD people. A food study in 1978 demonstrated that addition of red dye to fruit flavoured beverages increased the perceived sweetness by $5-10 \%$, while an addition of blue dye to cherry or strawberry flavoured beverages decreased sourness and fruit flavour by $20 \%$ [52].

Colours are often used to differentiate the different types of oral medications. Steward and Cole reported that some CVD subjects in their study had previously taken the wrong medications due to difficulties with colour [4]. Depending on what medication was taken, the adverse outcomes could range from insignificant to fatal. Patients who habitually mix their medications without the external packaging in the same pill storage compartment would be more prone to such hazards.

CVD may also affect the interpretation of coloured dipstick results used in healthcare $[5,17,53]$. A case-control study involving patients who had ACVI due to diabetic retinopathy showed that diabetics made significantly more errors in interpreting urinary glucose dipstick results than non-diabetic controls [53]. This would make monitoring of glycemic control more difficult, although monitoring is more commonly done via serum glucose today.

With increasing age and concurrent rising incidence of malignancies, detecting and awareness of colour-related signs and symptoms become important for susceptible individuals. Nonetheless, Spalding (1995) and Spalding (2004) mentioned difficulties in detecting hemoptysis, hematemesis, hematuria and bloody stools reported by these affected individuals $[5,17]$. Detecting these presenting symptoms early would allow earlier diagnosis and treatment of any underlying sinister conditions, such as lung cancer, upper gastrointestinal bleeds, bladder cancer and colorectal cancer.

\section{Discussion}

CVD is currently under-diagnosed as there is no structured screening in various parts of the world. Screening for CVD is important so that appropriate career advice can be given to these individuals, especially during the period when they are receiving their education [43]. This would require detection of CVD through screening using pseudoisochromatic tests, and then determining the type and severity via spectral and hue discrimination tests respectively. The Ishihara chart would be ideal for screening
Table 6 Recommendations for colour-coded designs

\begin{tabular}{ll}
\hline No. & Recommendations for colour-coded designs \\
\hline 1 & Avoid specific colours if no redundancy is possible \\
2 & $\begin{array}{l}\text { Include redundancy, especially lightness difference, whenever } \\
\text { possible }\end{array}$ \\
3 & Segment areas of colour which might otherwise be confused \\
4 & Avoid dark red or green text on a black background \\
5 & $\begin{array}{l}\text { Enhance colour conspicuity such as using white or yellow for } \\
\text { objects which have to be seen in poor illumination or at night }\end{array}$ \\
6 & Avoid glare
\end{tabular}

Data from Birch [23].

for congenital red-green colour blindness in children and should be made routine in schools. Currently, vision screening in schools in Singapore only includes visual acuity and stereopsis [54-56].

Nevertheless, screening for acquired CVD (ACVI) is challenging as they do not follow the well-defined patterns of congenital CVD and may be difficult to classify $[6,57]$. Currently, there is a paucity of primary studies to evaluate the costs and benefits of mass screening for acquired CVD, although some preliminary studies show that doing so may help detect diabetic retinopathy and primary open angle glaucoma earlier [8,58,59-62].

Once CVD has been detected via screening, measures must be taken to help the afflicted overcome their difficulties with colour discrimination. This is especially important as $46 \%$ of dichromats and $15 \%$ of anomalous trichomats reported colour difficulties with everyday work [4]. Means of overcoming occupational colour deficiencies used include asking others, using instruments, keeping objects of different colours in separate places and avoiding colour tasks [4]. A 2001 study showed that the use of tinted contact lenses in CVD subjects significantly reduced error rates on the Ishihara and Farnsworth Munsell D-15 test [62]. This may provide some assistance in colour-related

\section{Table 7 Steps for improving the classroom for CVD} children

\begin{tabular}{ll}
\hline No. & Steps for improving the classroom for CVD children \\
\hline 1 & Label felt tips, paints, pencils etc. \\
2 & Colour-code boxes of toys, art materials and books \\
3 & $\begin{array}{l}\text { Check computer-based teaching aids, web pages, computer } \\
\text { settings }\end{array}$ \\
4 & Use strong contrast on white or chalkboards. \\
5 & $\begin{array}{l}\text { Use patterns and labels rather than colours for maps, pie charts, } \\
\text { diagrams }\end{array}$ \\
6 & $\begin{array}{l}\text { In sports and games, ensure that children can see who is on his or } \\
\text { her 'team' }\end{array}$ \\
Group and label beads, bricks and colouring material according to \\
colour
\end{tabular}

Data from Albany-Ward K [16]. 
tasks. Tables 6 and 7 show recommendations for colourcoded designs made by Birch and simple steps for improving the classroom made by Albany-Ward K, the founder of the Colour Blind Awareness organisation [16,23].

\section{Conclusions}

CVD people face a wide range of difficulties in everyday life, especially for the dichromats. Many people are not aware of their CVD until they face difficulties differentiating colours or after they have undertaken colour vision testing. Screening for CVD is one possible intervention and should be carried out early in life. Increasing the awareness of CVD and its impact at the various stages of life will prompt the affected individuals to take on appropriate measures to ensure that CVD does not become their handicap.

\section{Abbreviations}

NCV: Normal colour vision; CVD: Colour vision deficiency; ACVI: Acquired colour vision impairment.

\section{Competing interests}

The authors declare that they have no competing interest.

\section{Authors' contributions}

TNC conceived the study. CV and GS conducted the literature review and drafted the article. TNC reviewed the drafts of the article. All authors read and approved the final manuscript.

\section{Author details}

'Ministry of Health Holdings Pte Ltd, 1 Maritime Square, \#11-25, Harbour Front Centre, Singapore 099253, Singapore. ${ }^{2}$ Research Department, SingHealth Polyclinics Head Office, 167 Jalan Bukit Merah, Connection One Tower 5, \#15-10, Singapore 150167, Singapore. 'DUKE-NUS Graduate Medical School, 8 College Rd, Singapore 169857, Singapore.

Received: 15 August 2013 Accepted: 19 September 2014

Published online: 09 October 2014

\section{References}

1. Spalding JA: Colour vision deficiency in the medical profession. $\mathrm{Br} J \mathrm{Gen}$ Pract 1999, 49(443):469-475.

2. Chia A, Gazzard G, Tong L, Zhang X, Sim E-L, Fong A, Saw SM: Red-green colour blindness in Singaporean children. Clin Experiment Ophthalmol 2008, 36(5):464-467.

3. Cole BL: The handicap of abnormal colour vision. Clin Exp Optom 2004, 87(4-5):258-275.

4. Steward JM, Cole BL: What do color vision defectives say about everyday tasks? Optom Vis Sci 1989, 66(5):288-295.

5. Spalding JAB: Confessions of a colour blind physician. Clin Exp Optom 2004, 87(4-5):344-349.

6. Formankiewicz M: Acquired colour vision deficiencies. In Optometry Today, Volume 49. ; 2009:37+

7. Lawrenson JG, Kelly C, Lawrenson AL, Birch J: Acquired colour vision deficiency in patients receiving digoxin maintenance therapy. $\mathrm{Br} J$ Ophthalmol 2002, 86(11):1259-1261.

8. Papaconstantinou D, Georgalas I, Kalantzis G, Karmiris E, Koutsandrea C, Diagourtas A, Ladas I, Georgopoulos G: Acquired color vision and visual field defects in patients with ocular hypertension and early glaucoma. Clin Ophthalmol 2009, 3:251-257.

9. Pinckers A, Marré M: Basic phenomena in acquired colour vision deficiency. Doc Ophthalmol 1983, 55(3):251-271.

10. Chan A, Hróbjartsson A, Haahr MT, Gøtzsche PC, Altman DG: Empirical evidence for selective reporting of outcomes in randomized trials: Comparison of protocols to published articles. JAMA 2004, 291(20):2457-2465.
11. Dwan K, Altman DG, Arnaiz JA, Bloom J, Chan AW, Cronin E, Decullier E, Easterbrook PJ, Von Elm E, Gamble C, Ghersi D, loannidis JP, Simes J, Williamson PR: Systematic Review of the Empirical Evidence of Study Publication Bias and Outcome Reporting Bias. PLoS One 2008, 3(8):e3081

12. Sullivan K: Colour-blind children. Special Educ Needs 2011, 12:21-23.

13. About Color Blindness (Color Vision Deficiency): Life's minor frustrations (and occasional dangers) for the color blind. In [http://www.toledo-bend. com/colorblind/aboutCB.asp]

14. Testing Color Vision: Frequently Asked Questions. In [http:// colorvisiontesting.com/color7.htm]

15. Sullivan K: The colour conundrum. In SecEd, Volume 15; 2011

16. Albany-Ward K: Why colour really does matter. In Prep School, Volume 15; 2011:36-37.

17. Spalding JAB: Doctors with inherited colour vision deficiency: their difficulties in clinical work. In Colour Vision Deficiencies XIII. Volume 59. Edited by Cavonius CR. The Netherlands: Springer Netherlands; 1997:483-489.

18. Mandola J: The role of color vision anomalies in elementary school achievement. J Sch Health 1969, 39(9):633-636.

19. Wilkinson WK: The cognitive and social-emotional correlates of color deficiency in children: a literature review and analysis. Adolescence 1992, 27(107):603-611.

20. Grassivaro Gallo P, Panza M, Viviani F, Lantieri PB: Congenital dyschromatopsia and school achievement. Percept Mot Skills 1998, 86(2):563-569.

21. Cumberland P, Rahi JS, Peckham CS: Impact of congenital colour vision deficiency on education and unintentional injuries: findings from the 1958 British birth cohort. BMJ 2004, 329(7474):1074-1075.

22. Tagarelli A, Piro A, Tagarelli G, Lantieri PB, Risso D, Olivieri RL: Colour blindness in everyday life and car driving. Acta Ophthalmol Scand 2004, 82(4):436-442.

23. Birch J: Diagnosis of defective colour vision: Butterworth-Heinemann; 2001.

24. Colour Vision Deficiency: Health Promotion Board; 2001.

25. Cole BL, Maddocks JD: Color vision testing by Farnsworth lantern and ability to identify approach-path signal colors. Aviat Space Environ Med 2008, 79(6):585-590.

26. Macdonald WA, Cole BL: Evaluating the role of colour in a flight information cockpit display. Ergonomics 1988, 31(1):13-37.

27. Birch J: Performance of colour-deficient people on the Holmes-Wright lantern (type A): consistency of occupational colour vision standards in aviation. Ophthalmic Physiol Opt 2008, 28(3):253-258.

28. Vingrys AJ, Cole BL: Validation of the Holmes - Wright lanterns for testing colour vision. Ophthalmic Physiol Opt 1983, 3(2):137-152.

29. Kinney JA, Paulson HM, Beare AN: The ability of color defectives to judge signal lights at sea. J Opt Soc Am 1979, 69(1):106-110.

30. Vingrys A, Cole B: The ability of colour defective observers to recognise an optimised set of red, green and white signal lights. In Colour Vision Deficiencies XI. Volume, Volume 56 . Edited by Drum B. The Netherlands: Springer Netherlands; 1993:87-95

31. Huang M, Bullough J, Boyce $P$, Bierman A: Detection and Identification of Light-Emitting Diode Traffic Signals by Protan Observers. Transport Res Rec 2003, 1844(1):52-58. 1844.

32. Culp G: Increasing Accessibility for Map Readers with Acquired and Inherited Colour Vision Deficiencies: A Re-Colouring Algorithm for Maps. Cartogr J 2012, 49(4):302-311.

33. Kuyk TK, Veres JG, Lahey MA, Clark DJ: Ability of deutan color defectives to perform simulated air traffic control tasks. Am J Optom Physiol Opt 1987, 64(1):2-10.

34. Mertens HW, Milburn NJ: Performance of color-dependent air traffic control tasks as a function of color vision deficiency. Aviat Space Environ Med 1996, 67(10):919-927.

35. Cole BL, Lian KY: Search for coloured objects in natural surroundings by people with abnormal colour vision. Clin Exp Optom 2006, 89(3):144-149.

36. Verriest G, Neubauer O, Marre M, Uvijls A: New investigations concerning the relationships between congenital colour vision defects and road traffic security. Int Ophthalmol 1980, 2(2):87-99.

37. Nathan J, Henry GH, Cole BL: Recognition of colored road traffic light signals by normal and color-vision-defective observers. J Opt Soc Am 1964, 54(8):1041-1045.

38. Atchison DA, Pedersen CA, Dain SJ, Wood JM: Traffic signal color recognition is a problem for both protan and deutan color-vision deficients. Hum Factors 2003, 45(3):495-503. 
39. O'Brien KA, Cole BL, Maddocks JD, Forbes AB: Color and defective color vision as factors in the conspicuity of signs and signals. Hum Factors 2002, 44(4):665-675.

40. Cole BL: Protan colour vision deficiency and road accidents. Clin Exp Optom 2002, 85(4):246-253.

41. Cole BL, Maddocks JD: Defective colour vision is a risk factor in driving. In Colour Vision Deficiencies XIII, Volume 59. Edited by Cavonius CR. The Netherlands: Springer Netherlands; 1997:471-481.

42. Norman LG: Medical aspects of road safety. Lancet 1960, 1(7133):1039-1045.

43. Taylor WO: Effects on employment of defects in colour vision. $\mathrm{Br} \mathrm{J}$ Ophthalmol 1971, 55(11):753-760.

44. Illumination ICo: Technical Report: International Recommendations for Colour Vision Requirements for Transport. Vienna, Austria: CIE Central Bureau; 2001.

45. Hovis JK, Oliphant D: A lantern color vision test for the rail industry. Am J Ind Med 2000, 38(6):681-696.

46. Vingrys AJ, Cole BL: Are colour vision standards justified for the transport industry? Ophthalmic Physiol Opt 1988, 8(3):257-274.

47. Dain SJ, Hughes LE: Survey of the Colour Vision Demands in Fire-Fighting. Oxford, United Kingdom: Oxford University Press; 2003.

48. Margrain T, Birch J: A suitable study to evaluate colour vision requirements for firefighters? Occup Med 1994, 44(5):257-258.

49. Margrain TH, Birch J, Owen CG: Colour vision requirements of firefighter. Occup Med (Lond) 1996, 46(2):114-124.

50. Davison SP, Myslinski NR: Shade selection by color vision-defective dental personnel. J Prosthet Dent 1990, 63(1):97-101.

51. Cumberland P, Rahi JS, Peckham CS: Impact of congenital colour vision defects on occupation. Arch Dis Child 2005, 90(9):906-908.

52. Kostyla AS, Clydesdale FM: The psychophysical relationships between color and flavor. CRC Crit Rev Food Sci Nutr 1978, 10(3):303-321.

53. Bresnick Gh GAPMKK: Urinary glucose testing inaccuracies among diabetic patients: Effect of acquired color vision deficiency caused by diabetic retinopathy. Arch Ophthalmol 1984, 102(10):1489-1496.

54. Vision Screening for Pre-School. [http://www.hpb.gov.sg/HOPPortal/healtharticle/520]

55. Health Screening for Primary School. [http://www.hpb.gov.sg/HOPPortal/ health-article/632]

56. Health Screening for Secondary School. [http://www.hpb.gov.sg/ HOPPortal/health-article/690]

57. Hong S: Types of acquired color-vision defects. AMA Arch Ophthalmol 1957, 58(4):505-509.

58. Roy Ms GRDPMJ: Color vision defects in early diabetic retinopathy. Arch Ophthalmol 1986, 104(2):225-228.

59. Fong DS, Barton FB, Bresnick GH: Impaired color vision associated with diabetic retinopathy: Early Treatment Diabetic Retinopathy Study Report No. 15. Am J Ophthalmol 1999, 128(5):612-617.

60. Rodgers M, Hodges R, Hawkins J, Hollingworth W, Duffy S, McKibbin M, Mansfield M, Harbord R, Sterne J, Glasziou P, Whiting P, Westwood M: Colour vision testing for diabetic retinopathy: a systematic review of diagnostic accuracy and economic evaluation. Health Technol Assess (Winchester, England) 2009, 13(60):1-160.

61. Pacheco-Cutillas M, Edgar DF, Sahraie A: Acquired colour vision defects in glaucoma-their detection and clinical significance. Br J Ophthalmol 1999, 83(12):1396-1402.

62. Swarbrick HA, Nguyen P, Nguyen T, Pham P: The ChromaGen contact lens system: colour vision test results and subjective responses. Ophthalmic Physiol Opt 2001, 21(3):182-196.

\section{Submit your next manuscript to BioMed Central and take full advantage of:}

- Convenient online submission

- Thorough peer review

- No space constraints or color figure charges

- Immediate publication on acceptance

- Inclusion in PubMed, CAS, Scopus and Google Scholar

- Research which is freely available for redistribution 